\title{
ESTRUTURA DO COMPONENTE EPÍFITO VASCULAR EM TRECHO DE FLORESTA ATLÂNTICA NA REGIÃO SERRANA DO ESPÍRITO SANTO ${ }^{1}$
}

\author{
Joelcio Freitas² e André Moreira de Assis ${ }^{3}$
}

\begin{abstract}
RESUMO - Este estudo teve como objetivo avaliar a comunidade epifítica de um fragmento de Floresta Atlântica da região centro serrana do estado do Espírito Santo, visando observar a distribuição dessa forma de vida sobre forófitos. O local de estudo é formado por uma encosta com floresta preservada que foi analisada no topo do morro (Área 1 - altitude de 890 m) e na meia encosta (Área 2 - 720 m de altitude). Foi adotado o método de quadrantes centrados, selecionando 15 pontos em cada área num total de 120 forófitos com DAP $\geq 10 \mathrm{~cm}$. Para a análise da distribuição das epífitas, os forófitos foram divididos nos estratos: fuste baixo, médio, alto, copa interna e externa. Para cada epífita foram atribuídas notas de frequência, que resultaram nos parâmetros fitossociológicos: valor de importância epifítico (VIe), dominâncias e frequências (absolutas e relativas). Foram registradas 29 espécies de epífitas e hemiepífitas, sendo Bromeliaceae (7 espécies) e Orchidaceae (6 espécies) as famílias mais representativas. Houve baixa similaridade entre as duas áreas (IS=0,3) com apenas cinco espécies em comum. As espécies com maior valor epifítico foram duas hemiepífitas: Heteropsis rigidifolia na Área $1(\mathrm{VIe}=29,1)$ e Polybotrya espiritosantensis na Área $2(\mathrm{VIe}=15,3)$, sendo o primeiro registro do gênero Polybotrya como importante táxon na estrutura epifítica. A riqueza foi baixa quando comparada a outros estudos com epífitas, porém a presença de espécies ameaçadas de extinção e raras demonstra a importância do remanescente florestal estudado para a conservação de táxons da Mata Atlântica.
\end{abstract}

Palavras-chaves: Fitossociologia; Epífitos; Floresta Ombrófila Densa.

\section{STRUCTURE OF VASCULAR EPIPHYTE COMPONENT IN A FRAGMENT OF THE ATLANTIC FOREST IN THE MOUNTAIN REGION OF ESPÍRITO SANTO}

\begin{abstract}
The objective of this study was to evaluate the epiphytic community from a fragment of the Atlantic Forest in the montainous region of Espirito Santo state, aiming at observing the distribution of this form of life on phorophytes. The study site is made up by a preserved forest hillside which was analyzed at the top of the hill (Area 1 - altitude of $890 \mathrm{~m}$ ) and on a slope (Area $2-720 \mathrm{~m}$ altitude). The method used in the experiment was the centered quarter, selecting 15 points for each area, totaling 120 phorophytes with $D B H \geq 10 \mathrm{~cm}$. For the analysis of epiphytes distribution, the phorophytes were divided into the following strata: low, medium and high shaft, internal and external canopy. Each epiphyte received a frequency grade, resulting in the phytosociological parameters: epiphytic importance (VIe), dominance and frequency (absolute and relative). Twenty-nine species of epiphytes and hemiepiphytes were recorded, and the most representative families were Bromeliaceae (7 species) and Orchidaceae (6 species). There was a low similarity between the two areas (IS $=0.3$ ) with only five species in common. The species with the highest epiphytic importance were two hemiepiphytes: Heteropsis rigidifolia in Area 1 (VIe $=29.1$ ) and Polybotrya espiritosantensis in Area 2 (Vie = 15.3), the first record of the genus Polybotrya as important taxon in epiphytic structure. The richness was low compared to other studies with epiphytes, however, the presence of rare and endangered species demonstrates the importance of the studied forest for the conservation of taxons in the Atlantic Forest.
\end{abstract}

Keywords: Epiphytes; Phytosociology; Rain Forest.

\footnotetext{
${ }^{1}$ Recebido em 05.04.2012 aceito para publicação em 13.08.2013.

${ }^{2}$ Museu de Biologia Prof. Mello Leitão, MBML, Santa Teresa, ES, Brasil. E-mail: <joelciofr@gmail.com>.

${ }^{3}$ Escola Superior São Francisco de Assis, ESFA, Santa Teresa, ES, Brasil. E-mail: <andremassis@gmail.com>.
} 


\section{INTRODUÇÃO}

As epífitas vasculares perfazem cerca de $10 \%$ da flora total mundial, sendo representadas por diversas espécies de Orchidaceae, Bromeliaceae, Cactaceae e Samambaias (GENTRY; DODSON, 1987).

Espécies epífitas são muito importantes, pois são responsáveis por fazerem das florestas tropicais e subtropicais um dos mais complexos ecossistemas da biosfera, sendo estes ambientes representados por até 50\% de espécies epífitas (KESTERN; SILVA, 2001). Nas florestas tropicais representam a maioria das espécies em locais onde a umidade relativa do ar se mantém elevada durante o ano (GENTRY; DODSON, 1987).

A dependência de substrato arbóreo em associação à sensibilidade a umidade faz com que as epífitas sejam indicadores ecológicos eficientes, registrando tanto a qualidade dos ecossistemas quanto as variações ambientais naturais (TRIANA-MORENO et al., 2003).

Os principais trabalhos com estrutura de epífitas começaram a ser realizados no Brasil a partir da década de 1980, sendo o trabalho de Waechter (1980) um dos precursores do assunto no Brasil, com destaque também, para os estudos de Aguiar et al. (1981), Fontoura et al. (1997), Giongo e Wachter (2004), Kersten (2006), Kersten e Kuniyoshi (2009), Kersten e Silva (2001, 2005), Santos (2008).

Contudo, apesar do esforço crescente dos pesquisadores, especialmente na última década, o conhecimento acumulado a respeito destas plantas ainda é insuficiente diante da sua importância para as florestas tropicais (GIONGO; WAECHTER, 2004).

É preciso dar maior ênfase à esses estudos, haja vista relevância das espécies epífitas para os diversos habitats, principalmente na mata atlântica da região serrana capixaba, que ainda apresenta grande percentual de cobertura vegetal florestal, tal como no município de SSanta Maria de Jetibá, com 26\% (18.834 ha) dos seus remanescentes preservados (FUNDAÇÃO SOS MATA ATLÂNTICA; INPE, 2013). No estado do Espírito são escassos trabalhos acerca da estrutura do componente epifítico, registrando-se estudos sobre flora de algumas famílias botânicas com muitos representantes epífitos, tais como Fraga e Peixoto (2004), Pereira e Ribeiro (2004), Rodrigues e Simonelli (2007) e Wendt et al., (2010).
Diante do exposto objetivou-se avaliar a comunidade de epífitas vasculares em áreas de floresta ombrófila densa montana na região centro serrana do Estado do Espírito Santo, além de reconhecer padrões de distribuição geográfica e status de conservação das espécies.

\section{MATERIAIS E MÉTODOS}

\section{1. Área de Estudo}

O Município de Santa Maria de Jetibá possui cerca de 736,30 $\mathrm{km}^{2}$ e forte declividade, com altitude variando entre 400 e $1.200 \mathrm{~m}$, e temperatura média em torno de $22,3^{\circ} \mathrm{C}$, apresentando inverno seco e verão chuvoso, sendo a maior ocorrência de chuvas no período de novembro a março (SEFAZ, 2010), e a precipitação anual na região estudada de 1.200 mm (SILVA et al., 2011).

O estudo desenvolveu-se na comunidade de São José do Rio Claro, entre as coordenadas aproximadas 2000'44.82'”S e 40³6'53.58'”'W, a $32 \mathrm{~km}$ da sede do município, compreendendo trechos de Mata Atlântica interligados entre si, com variação de 630 a 900 m de altitude.

O local estudado é formado por uma encosta com floresta preservada que foi analisada no topo do morro (Área 1), que atinge altitude de 890 m, e na meia encosta (Área 2), cuja altitude é de 720 m. Segundo informações de moradores locais essas áreas nunca foram alvo de corte ou sofreram ação de fogo. O dossel nesta floresta atinge altura média de 12 metros, com emergentes de 22 m e 25 m nas áreas 1 e 2, respectivamente, tendo também nessa última exemplares arbóreos de maior porte diamétrico.

\subsection{Coleta e identificação do material botânico}

Foram realizadas campanhas de campo quinzenais, com duração de um ou dois dias cada, no período de agosto de 2010 à março de 2011, onde foram coletadas plantas férteis para inclusão no Herbário MBML, de acordo com procedimentos propostos por Mori et al. (1989). Alguns exemplares estéreis que se apresentaram com potencial de serem diferentes das espécies coletadas ou amostradas, foram levados para a Coleção de Plantas Vivas do Museu de Biologia Mello Leitão, com finalidade de acompanhamento do seu estádio reprodutivo e posterior inclusão no Herbário, após sua floração/ frutificação. 
A identificação das espécies realizou-se por meio de literatura especializada e por comparação com exsicatas registradas no Herbário MBML. Em alguns casos os espécimes foram enviadas à especialistas do grupo taxonômico referente para confirmação da identificação. A determinação das autorias taxonômicas foi realizada de acordo com a base de dados Tropicos (http:// www.tropicos.org).

\subsection{Levantamento fitossociológico (epífitas e forófitos)}

A estrutura da comunidade epifítica foi avaliada por meio da distribuição das espécies nos seus respectivos forófitos, adotando o método proposto por BraunBlanquet (1979), da qual divide o forófito em zonas ecológicas: Fuste Baixo (FB) (da base do tronco até 1,30 m), Fuste Alto (FA) (de 1,30 m abaixo da base da copa), Fuste Médio (FM) (intervalo de espaço entre o fuste baixo e o fuste alto), Copa Interna (CI) (parte interna da copa, 50\% do comprimento dos galhos) e Copa externa (CE) (parte externa da copa, 50\% do comprimento dos galhos).

A amostragem dos forófitos se deu por meio do método de quadrantes centrados (MARTINS, 1991), da qual foram selecionados cinco pontos eqüidistantes entre si ao longo de três trilhas pré-estabelecidas em cada área (topo do morro e meia-encosta), com um total de 30 pontos nos dois locais amostrados, considerando indivíduos com DAP (diâmetro à altura do peito) $\geq$ $10 \mathrm{~cm}$.

A quantificação das epífitas se deu por observação através de binóculos e câmeras fotográficas, além do auxílio de podão para coleta dos materiais férteis ou com identificação deficiente à distância. Foram atribuídas notas aos epífitos presentes em cada segmento estrutural, de acordo com metodologia de Kersten (2006), que adotou cinco categorias com os seguintes pressupostos: quanto maior a biomassa da espécie na zona, maior será a nota; e uma nota máxima pode ser atribuída tanto a um único indivíduo de grande porte quanto a um grande número de indivíduos de médio porte.

Com base em Kersten (2006) a pontuação foi: nota 1 - indivíduos muito pequenos isolados; nota 3 - poucos indivíduos pequenos; nota 5 - indivíduos médios, ou muitos indivíduos pequenos; nota 7 - indivíduos de grande porte ou muitos indivíduos de médio porte; nota 10 - indivíduos muito grandes ou muitos indivíduos de grande porte.
Espécies hemiepífitas, de um mesmo indivíduo, que estivesse presente em 2 estratos diferentes, foram anotados na planilha como um indivíduo encontrado em ambos os estratos, porém com apenas uma atribuição de nota.

Como parâmetros fitossociológicos das espécies em cada área foram considerados o Valor de Importância Epifítico (VIE), Dominância absoluta (DoA), Dominância relativa (DoR), Frequência absoluta sobre os forófitos (FfA), Frequência relativa sobre os forófitos (FfR), Frequência absoluta sobre as zonas ecológicas (FzA) e Frequência relativa sobre as zonas ecológicas (FzR) conforme proposto por Kersten, 2006.

Foi realizada análise de similaridade florística entre as áreas estudadas, por meio do Índice de Sorensen (IS) (MUELLER-DOMBOIS; ELLENBERG, 1974), utilizando o software FITOPAC 1.6.4(SHEPHERD, 2006).

O reconhecimento do status de conservação se baseou na presença das espécies nas listas de ameaçadas de extinção, em âmbito internacional (IUCN, 2010), nacional (BRASIL, MMA, 2008) e estadual (ESPÍRITO SANTO, 2005).

\section{RESULTADOS}

Foi registrado no estudo quantitativo dos 120 forófitos analisados, um total de 29 espécies de epífitas e hemiepífitas vasculares (Tabela 1), distribuídas em 15 gêneros e 5 famílias. As famílias com maior riqueza foram Bromeliaceae (7 espécies) e Orchidaceae (6 espécies) e o gênero foi Tillandsia, com 5 espécies.

Foram registradas 19 espécies de epífitas e hemiepífitas na área 2 e 15 na área 1.

As duas famílias com maior riqueza (Orchidaceae e Bromeliaceae) representam 44,82 \% das espécies encontradas.

Na amostragem vertical dos táxons, houve um predomínio de espécies hemiepífitas nas duas áreas amostradas, sendo que Heteropsis rigidifolia (na área 1) e Polybotrya espiritosantensis (na área 2) tiveram o maior Valor de Importância Epifítico (VIE), 29,1 e 15,3, respectivamente (Tabelas 2 e 3).

O número de ocorrência de epífitos em um mesmo forófito variou de 1 a 8 espécies. O táxon Pouteria sp (Sapotaceae) foi o forófito com o maior número de epífitos (8).

Revista Árvore, Viçosa-MG, v.37, n.5, p.815-823, 2013 
Tabela 1 - Listagem geral (Áreas 1 e 2) das espécies de epífitas encontradas na floresta atlântica em São José do Rio Claro, Santa Maria de Jetibá, ES. Hábito: EP = epífito; e HE = hemiepífito.

Table 1 - Overall Row (areas 1 and 2)of the species of epiphytes found in the Atlantic Forest in São José do Rio Claro, Santa Maria de Jetibá (ES). Habit: EP= epiphyte, $H E=$ hemiepiphyte.

\begin{tabular}{|c|c|c|c|c|}
\hline Família & Espécie & Hábito & Área 1 & Área 2 \\
\hline Araceae & Anthurium coriaceum G. Don & EP & & $X$ \\
\hline Araceae & Anthurium pentaphyllum (Aubl.) G.Don & EP & & $\mathrm{X}$ \\
\hline Araceae & Araceae sp & $\mathrm{HE}$ & $\mathrm{X}$ & \\
\hline Araceae & Heteropsis rigidifolia Engl. & $\mathrm{HE}$ & $\mathrm{X}$ & \\
\hline Araceae & Philodendron propinquum Schott & EP & & $\mathrm{X}$ \\
\hline Bromeliaceae & Aechmea cf castanea L. B. Sch. & EP & & $\mathrm{X}$ \\
\hline Bromeliaceae & Tillandsia gardnerii Lindl. & EP & $\mathrm{X}$ & \\
\hline Bromeliaceae & Tillandsia kautskyi E.Pereira & $\mathrm{EP}$ & $\mathrm{X}$ & \\
\hline Bromeliaceae & Tillandsia sp & EP & $\mathrm{X}$ & \\
\hline Bromeliaceae & Tillandsia tenuifolia $\mathrm{L}$. & EP & & $X$ \\
\hline Bromeliaceae & Tillandsia usneoides (L.) L. & EP & & $\mathrm{X}$ \\
\hline Bromeliaceae & Vriesea procera (Mart. ex Schult. e Schult.f.) Wittm & EP & $X$ & \\
\hline Cactaceae & Hatiora salicornioides (Haw.) Britton e Rose & EP & & $\mathrm{X}$ \\
\hline Cactaceae & Rhipsalis cf flocosa Salm-Dyck ex Pfeiff & EP & $\mathrm{X}$ & $\mathrm{X}$ \\
\hline Dryopteridaceae & Polybotrya espiritosantensis Brade & $\mathrm{HE}$ & $\mathrm{X}$ & $\mathrm{X}$ \\
\hline Indeterminada & Hemiepífita sp. & $\mathrm{HE}$ & & $\mathrm{X}$ \\
\hline Indeterminada & Pteridophyta sp. & $\mathrm{HE}$ & & $\mathrm{X}$ \\
\hline Indeterminada & Pteridophyta sp2 & $\mathrm{HE}$ & & $\mathrm{X}$ \\
\hline Indeterminada & Pteridophyta sp3 & & & $\mathrm{X}$ \\
\hline Loganiaceae & Strychnos sp & $\mathrm{HE}$ & & $\mathrm{X}$ \\
\hline Orchidaceae & Christensonella subulata (Lindl.) Szlach. et al & EP & & $\mathrm{X}$ \\
\hline Orchidaceae & Gomesa pubes (Lindl.) M.W.Chase e N.H.Williams & EP & $\mathrm{X}$ & $\mathrm{X}$ \\
\hline Orchidaceae & Leptotes cf tenuis Rchb.f. & EP & $\mathrm{X}$ & $\mathrm{X}$ \\
\hline Orchidaceae & Mormolyca cf rufescens (Lindl.) M.A.Blanco & EP & & $\mathrm{X}$ \\
\hline Orchidaceae & Pleurothallis sp. & EP & $\mathrm{X}$ & \\
\hline Orchidaceae & Prostechea calamaria (Lindl.) W.E.Higgins & EP & $\mathrm{X}$ & \\
\hline Polypodiaceae & Mickelia guianensis (Aubl.) R.C. Moran, Sundue e Labiak & $\mathrm{HE}$ & & $\mathrm{X}$ \\
\hline Polypodiaceae & Microgramma squamulosa (Kaulf.) de la Sota & EP & & $\mathrm{X}$ \\
\hline Polypodiaceae & Serpocaulon catharinae (Langsd. e Fisch.) A.R.Sm. & $\mathrm{HE}$ & $\mathrm{X}$ & \\
\hline
\end{tabular}

Das espécies de epífitas encontradas na Área 1, 15 delas ocorreram em apenas uma das zonas ecológicas. Contudo, destas, 11 tiveram apenas um registro, o que não leva a concluir, que tenham uma preferência por algum estrato específico. Por outro lado, duas espécies tiveram uma preferência por determinado fuste, Tillandsia sp. (Fuste Médio), sendo registrada em três forófitos e Vriesea procera amostrada quatro vezes, todas em Fuste Baixo. Outra espécie que merece destaque, na preferência de determinado fuste, é a Polybotrya espiritosantensis, onde de seus oito indivíduos registrados, sete ocorreram no Fuste Baixo e apenas um no Fuste Médio.

Das 19 espécies encontradas na área 2, 11 delas ocorreram em apenas 1 fuste. Porém estes foram os únicos registros dessas espécies, o que também não indica que estas tenham alguma preferência por determinada zona ecológica. Porém, algumas espécies tiveram uma ocupação maior em determinado estrato arbóreo. Christensonella subulata, com dois registros, foi encontrada apenas na Copa Interna. As espécies Polybotrya espiritosantensis e Mickelia guianensis tiveram uma preferência maior pelos fustes mais baixos, P. espiritosantensis principalmente pelo Fuste Baixo, com 6 das 7 ocorrências da espécie e $M$. guianensis com 3 ocorrências no Fuste Baixo e 3 no Fuste Médio. Tillandsia usneoides, foi encontrada apenas nos estratos superiores dos forófitos. Dos 7 registros para a espécie, 3 deles foram sobre a Copa Externa e 4 na Copa Interna.

Na área 2 o número de espécies epífitas (19) foi maior que na Área 1 (15), possuindo apenas cinco táxons em comum nas duas florestas analisadas, o que resultou 
Tabela 2 - Espécies ocorrentes no levantamento quantitativo, na Área 1, em ordem do valor de importância epifítica (VIE) (nf = número de forófitos com a espécie epifítica, $\mathrm{FfA}$ = frequência absoluta sobre os forófitos, FfR = frequência relativa sobre os forófitos, $\mathrm{DoA}$ = dominância absoluta, $\mathrm{DoR}$ = dominância relativa, $\mathrm{nz}$ = número de zonas ecológicas em que a espécie epifítica foi observada, FzA = frequência absoluta sobre as zonas ecológicas e FzR = frequência relativa sobre as zonas ecológicas).

Table 2 - Species found in the quantitative survey, in area 1, in order of epiphytic importance value (VIE) (nf = number of host-trees with epiphytic species, FFA = absolute frequency on phorophytes, FFR = relative frequency on phorophytes, $D o A=$ absolute dominance, $D o R=$ relative dominance, $n z=$ number of ecological zones where the species observed was epiphytic, FZA = absolute frequency on ecological zones and FZR = relative frequency on ecological zones).

\begin{tabular}{|c|c|c|c|c|c|c|c|c|c|}
\hline Espécie & $\mathrm{Nf}$ & FfA & FfR & DoA & DoR & VIE & $\mathrm{nz}$ & FzA & FzR \\
\hline Heteropsis rigidifolia & 7 & 11,7 & 20,6 & 56 & 37,6 & 29,1 & 5 & 100 & 23,8 \\
\hline Tillandsia cf gardneri & 5 & 8,3 & 14,7 & 11 & 7,4 & 11 & 2 & 40 & 9,5 \\
\hline Vriesea procera & 3 & 5,0 & 8,8 & 18 & 12,1 & 10,4 & 1 & 20 & 4,8 \\
\hline Tillandsia kautskyi & 3 & 5 & 8,8 & 9 & 6,0 & 7,4 & 2 & 40 & 9,5 \\
\hline Tillandsia sp. & 3 & 5 & 8,8 & 5 & 3,4 & 6,1 & 1 & 20 & 4,8 \\
\hline Tillandsia tenuifolia & 2 & 3,3 & 5,9 & 9 & 6 & 6 & 1 & 20 & 4,8 \\
\hline Pteridophyta sp. & 2 & 3,3 & 5,9 & 4 & 2,7 & 4,3 & 1 & 20 & 4,8 \\
\hline Polybotrya espiritosantensis & 1 & 1,7 & 2,9 & 7 & 4,7 & 3,8 & 1 & 20 & 4,8 \\
\hline Gomesa pubes & 1 & 1,7 & 2,9 & 5 & 3,4 & 3,1 & 1 & 20 & 4,8 \\
\hline Rhipsalis cf flocosa & 1 & 1,7 & 2,9 & 5 & 3,4 & 3,1 & 1 & 20 & 4,8 \\
\hline Leptotes cf tenuis & 1 & 1,7 & 2,9 & 3 & 2 & 2,5 & 1 & 20 & 4,8 \\
\hline Pleurothallis sp. & 1 & 1,7 & 2,9 & 3 & 2 & 2,5 & 1 & 20 & 4,8 \\
\hline Prostechea calamaria & 1 & 1,7 & 2,9 & 3 & 2 & 2,5 & 1 & 20 & 4,8 \\
\hline Pteridophyta sp2. & 1 & 1,7 & 2,9 & 3 & 2 & 2,5 & 1 & 20 & 4,8 \\
\hline Serpocaulon catharinae & 1 & 1,7 & 2,9 & 1 & 0,7 & 1,8 & 1 & 20 & 4,8 \\
\hline
\end{tabular}

Tabela 3 - Espécies ocorrentes no levantamento quantitativo, na área 2, em ordem do valor de importância epifítica (VIE) (nf = número de forófitos com a espécie epifítica, FfA = frequência absoluta sobre os forófitos, FfR = frequência relativa sobre os forófitos, $\mathrm{DoA}$ = dominância absoluta, $\mathrm{DoR}$ = dominância relativa, $\mathrm{nz}$ = número de zonas ecológicas onde a espécie epifítica foi observada, FzA = frequência absoluta sobre as zonas ecológicas e FzR = frequência relativa sobre as zonas ecológicas).

Table 3 - Species found in the quantitative survey in area 2, in order of epiphytic importance value (VIE) (nf $=n$ number of host-trees with epiphytic species, FfA = absolute frequency on phorophytes, $F f R=$ relative frequency on phorophytes, $D o A=$ absolute dominance, $D o R=$ relative dominance, $n z=$ number of ecological zones where the species observed was epiphytic, FzA = absolute frequency on ecological zones, FzR = relative frequency on ecological zones).

\begin{tabular}{|c|c|c|c|c|c|c|c|c|c|}
\hline Espécie & $\mathrm{Nf}$ & FfA & FfR & DoA & DoR & VIE & $\mathrm{nz}$ & FzA & FzR \\
\hline Polybotrya espiritosantensis & 5 & 8,3 & 14,7 & 31 & 16 & 15,3 & 2 & 40 & 7,7 \\
\hline Tillandsia usneoides & 4 & 6,7 & 11,8 & 27 & 13,9 & 12,8 & 2 & 40 & 7,7 \\
\hline Mickelia guianensis & 3 & 5 & 8,8 & 20 & 10,3 & 9,6 & 2 & 40 & 7,7 \\
\hline Anthurium coriaceum & 3 & 5 & 8,8 & 19 & 9,8 & 9,3 & 2 & 40 & 7,7 \\
\hline Philodendron propinquum & 3 & 5 & 8,8 & 15 & 7,7 & 8,3 & 2 & 40 & 7,7 \\
\hline Heteropsis rigidifolia & 2 & 3,3 & 5,9 & 15 & 7,7 & 6,8 & 2 & 40 & 7,7 \\
\hline Microgramma squamulosa & 2 & 3,3 & 5,9 & 7 & 3,6 & 4,7 & 2 & 40 & 7,7 \\
\hline Christensonella subulata & 2 & 3,3 & 5,9 & 6 & 3,1 & 4,5 & 1 & 20 & 3,8 \\
\hline Aechmea cf castanea & 1 & 1,7 & 2,9 & 10 & 5,2 & 4 & 1 & 20 & 3,8 \\
\hline Pteridophyta sp3. & 1 & 1,7 & 2,9 & 10 & 5,2 & 4 & 2 & 40 & 7,7 \\
\hline Araceae sp. & 1 & 1,7 & 2,9 & 7 & 4,7 & 3,8 & 1 & 20 & 3,8 \\
\hline Rhipsalis flocosa & 1 & 1,7 & 2,9 & 7 & 3,6 & 3,3 & 1 & 20 & 3,8 \\
\hline Anthurium pentaphyllum & 1 & 1,7 & 2,9 & 5 & 2,6 & 2,8 & 1 & 20 & 3,8 \\
\hline Hatiora cf salicornioides & 1 & 1,7 & 2,9 & 5 & 2,6 & 2,8 & 1 & 20 & 3,8 \\
\hline Strychnos sp & 1 & 1,7 & 2,9 & 5 & 2,6 & 2,8 & 1 & 20 & 3,8 \\
\hline Gomesa pubes & 1 & 1,7 & 2,9 & 5 & 2,6 & 2,8 & 1 & 20 & 3,8 \\
\hline Hemiepífita sp. & 1 & 1,7 & 2,9 & 3 & 1,5 & 2,2 & 1 & 20 & 3,8 \\
\hline Maxillaria cf rufescens & 1 & 1,7 & 2,9 & 3 & 1,5 & 2,2 & 1 & 20 & 3,8 \\
\hline Tillandsia tenuiflora & 1 & 1,7 & 2,9 & 1 & 0,5 & 1,7 & 1 & 20 & 3,8 \\
\hline
\end{tabular}


em uma baixa similaridade $(0,3)$. Dentre as espécies em comum, apenas Heteropsis rigidifolia e Polybotrya espiritosantensis apresentam elevado Valor de Importância Epifítica, com as demais ocupando posições inferiores quanto a esse parâmetro. Apesar de ocorrerem nos dois trechos de floresta estudados, $H$. rigidifolia e $P$. espiritosantensis ocorrem com alto VIE apenas na Área 1 e na Área 2, respectivamente.

A maioria dos indivíduos arbóreos amostrados na fitossociologia não apresentou epífitas, tanto na Área 1 (68\% dos indivíduos) quanto na Área 2 (70\%), um padrão também encontrado por Santos (2008). Porém observa-se uma preferência no epifitismo para alguns táxons arbóreos, como Vochysia santaluciae (Vochysiaceae), Byrsonima aff. cacaophila (Malphighiaceae), Pouteria sp (Sapotaceae) e Ocotea cf. lancifolia (Lauraceae), que apresentam maior número de indivíduos e espécies epífitas.

\section{DISCUSSÃO}

O número de espécies epífitas encontrado no estudo foi baixo, se comparado a outros trabalhos realizados com estrutura de epífitas em florestas ombrófilas. Kersten (2006) encontrou em estudo realizado no Paraná, 143 espécies enquanto Fontoura et al. (1997) registrou 308 táxons no Rio de Janeiro. Comparado com o trabalho de Santos (2008), realizado em São Paulo, verifica-se que a discrepância no número de espécies não é tão elevada, pois foram registradas 40 espécies, embora nesse estudo parte da área estudada represente floresta secundária, cujas condições ambientais desfavorecem o desenvolvimento de epífitas (FONTOURA et al., 1997).

A escassez de cursos hídricos no local poderia explicar a menor riqueza de epífitas no presente estudo, uma vez que contribuem com o aumento de umidade, tão importante para o desenvolvimento dessas plantas (TONHASCA JR., 2005), ressaltando-se que não há registro de impactos antrópicos sobre a floresta estudada. A influência desse componente abiótico nas epífitas locais foi observada durante um levantamento florístico que englobou, além da presente área de estudo, um morro adjacente cuja floresta é mais úmida e existe um pequeno córrego, onde se encontrou maior número de espécies (51) que na área da fitossociologia (37) (FREITAS, 2011). A carência deste fator foi também levantada por Rech et al. (2011), onde a disposição de um espelho d'água, poderia favorecer a abundância maior de epífitos, na parte vertical do forófito, voltada para a porção sul da área, onde este corpo hídrico estava localizado.

Comparando as espécies com maior Valor de Importância Epifítico (VIE) nas duas áreas, H. rigidifolia, teve praticamente o dobro do VIE $(29,1)$ perante a segunda espécie mais importante (Polybotrya espiritosantensis - 15,3), e foi registrada em 8,3\% dos forófitos. Além disso, ocorreu em todas as zonas ecológicas, com predominância nas zonas de fuste (principalmente o fuste médio).

Dados de VIE altos para $H$. rigidifolia foram também observados em uma floresta ombrófila densa no estado do Paraná, onde obteve maior valor de importância dentre as epífitas analisadas no estudo de Petean (2009). Como o táxon P. espiritosantensis é endêmico do Espírito Santo (PRADO, 2012) e não existem trabalhos sobre a estrutura epifítica nesse estado não é possível inferir sobre sua importância em outras localidades. Não foram encontrados registros de outras espécies de Polybotrya com destaque na composição fitossociológica das epífitas na mata atlântica brasileira (PETEAN, 2009; KERSTEN, 2006; KERSTEN; KUNIYOSHI, 2009; KERSTEN; SILVA, 2001; 2005; GIONGO;WACHTER, 2004; SANTOS, 2008), podendo ser um padrão das florestas da região serrana central do Espírito Santo.

O hemiepifitismo não é uma forma de vida importante no estrato superior das florestas tropicais brasileiras (BLUM et al., 2011; BUZATTO et al., 2008; KERSTEN, 2006; KERSTEN; KUNIYOSHI, 2009; KERSTEN; SILVA, 2001; 2005; GIONGO; WACHTER, 2004;) registrado com destaque apenas no trabalhos de Santos (2008) e Petean (2009). Esse predomínio pode estar relacionado à menor oferta hídrica, especialmente a umidade do ar, na encosta estudada, em função da ausência de cursos d'água no local, onde os organismos hemiepífitos estariam ocupando melhor os estratos florestais, por obterem os recursos diretamente do solo, em detrimento das demais epífitas que dependem apenas da precipitação e umidade do ar para sua nutrição, uma vez que as condições ambientais do dossel normalmente são mais xéricas que no solo (BENZING, 1990; LARCHER, 2006).

Assim como observado em outros trabalhos com estrutura de epífitas em Florestas Ombrófilas Densas no Brasil(KERSTEN; SILVA, 2005; PETEAN, 2009; BLUM et al., 2011) Orchidaceae e Bromeliaceae sempre obtiveram, juntas, um número elevado de riqueza epifítica. 
Se comparado a outros estudos com estrutura de epífitos no país, o numero de espécies epifíticas sobre um mesmo forófito foi baixo. O máximo de epífitos num mesmo indivíduo arbóreo segundo Kersten (2006) foi 14, 17, 24 e 31 nas quatro áreas estudadas na bacia do Alto Iguaçu (PR). No estudo de Petean (2009) observou-se 79 epífitas sobre um mesmo forófito e em Kersten (2001) verificou-se a presença de 35 espécies epifíticas sobre um mesmo indivíduo arbóreo. Novamente o fator baixa umidade pode estar contribuindo para essa menor abundância de epífitos na floresta estudada em Santa Maria de Jetibá.

A baixa similaridade entre as áreas $(0,3)$, com 5 espécies em comum, permite inferir que as áreas de estudo apresentem flora epifítica própria e distinta, podendo ser resultado de variações microclimáticas nesses dois locais, que é um importante fator no estabelecimento de epífitas, conforme indicam Santos (2008) e Pereira (2009). Essa variação estaria relacionada a diferenças na estrutura do componente forofítico, como a densidade e desenvolvimento diamétrico, já que a Área 1 apresenta indivíduos finos e adensados que permitem maior incidência luminosa que na Área 2, com exemplares esparsos e de grande porte, que tornam o ambiente mais sombreado e úmido.

Kersten e Silva (2001, 2005), assim como registrado neste trabalho, encontraram o gênero Ocotea como importante forófito na floresta atlântica do Paraná, indicando ser um táxon importante para o desenvolvimento do epifitismo nesse bioma.

De acordo com Benzing (1990) fatores intrínsecos dos forófitos como tamanho, idade, arquitetura da árvore e características da casca influenciam na ocorrência de epífitos. Dos forófitos com importância maior para este trabalho, apenas Byrsonima aff. cacaophila não está dentre os indivíduos de maior porte na floresta analisada, porém apresenta copa e galhos que favorecem o estabelecimento das epífitas. As outras espécies (Vochysia santaluciae, Pouteria sp e Ocotea cf. lancifolia), além do porte e arquitetura, possuem outro item de prevalência por epífitas, o caule fissurado, que possibilita melhor fixação das sementes dos grupos vegetais epífitos.

Apesar da baixa riqueza epifítica, a comunidade estudada em São José do Rio Claro abriga táxons de importância conservacionista. Em termos de endemismo podemos citar Polybotrya espiritosantensis e Tillandsia kautskyi ocorrentes apenas na região serrana capixaba (PRADO; 2011; FORZZA et al., 2011) e dentre as ameaçadas de extinção, estão a própria Tillandsia kautskyi que encontra-se na lista estadual das espécies, enquadrada na categoria EN (Em perigo) e na lista nacional de espécies ameaçadas na categoria VU (Vulnerável), além de Anthurium coriaceum presente na lista estadual, enquadrado como Vulnerável. Destaca-se ainda a ocorrência de Aechmea cf. castanea e T. kautskyi, consideradas espécies raras da flora brasileira (GIULIETTI et al., 2009), demonstrando a importância da localidade de estudo para a conservação in situ de importantes elementos da flora capixaba.

\section{CONCLUSÃO}

Os trabalhos quantitativos sobre o grupo ecológico das epífitas no estado do Espírito Santo são relativamente escassos, assim como no restante da Mata Atlântica brasileira. A bibliografia sobre esse tema demonstra uma inconstância temporal nas publicações com maior concentração dos trabalhos realizados na região sul do Brasil.

Apesar de uma baixa riqueza de epífitas perante outros trabalhos, a notoriedade deste trabalho se faz presente pela ocorrência de espécies ameaçadas da nossa flora (estadual e nacional) no levantamento, assim como de espécies vegetais endêmicas e raras.

Considerando que São José do Rio Claro é uma localidade pouco explorada em termos científicos, trabalhos como esse reforçam a necessidade de se estudar os remanescentes da Mata Atlântica no estado do Espírito Santo.

\section{AGRADECIMENTOS}

Ao Museu de Biologia Prof. Mello Leitão, em especial Helio de Queiroz Boudet Fernandes por permitir a utilização das instalações do Herbário MBML. Ao Alfredo Renok e Claúdio de Almeida Conceição por permitir os estudos em suas propriedades. Ao Ludovic J. C. Kollmann pelo auxílio na identificação das espécies. Ao Filipe Soares de Souza pela identificação das pteridofitas. À Escola Superior São Francisco de Assis (ESFA) pela concessão da bolsa de Iniciação Científica ao primeiro autor.

Revista Árvore, Viçosa-MG, v.37, n.5, p.815-823, 2013 


\section{REFERÊNCIAS}

AGUIAR, L. W. et al. Composição florística de epífitos vasculares numa área localizada nos municípios de Montenegro e Triunfo, Rio Grande do Sul, Brasil. Iheringia, Série Botânica v.28, p.55-93, 1981.

BENZING, D. H. Vascular epiphytes.

Cambridge: Cambridge University Press, 1990. 334p.

BLUM, C. T.; RODERJAN, C. V.; GALVÃO, F. Composição florística e distribuição altitudinal de epífitas vasculares da Floresta Ombrófila Densa na Serra da Prata, Morretes, Paraná, Brasil. Biota Neotropica, v.11, n.4, p.141-159, 2011.

BRAUN-BLANQUET, J. Fitossociologia: bases para el estudio de las comunidades vegetales. Madri: $H$. Blume Ediciones, 1979. 820p.

BRASIL. Ministério do Meio Ambiente. Instrução Normativa ${ }^{\circ}$ 6, de 23 de setembro de 2008.

Lista Oficial das Espécies da Flora Brasileira Ameaçadas de Extinção IBAMA. Brasília: 2008.

BUZATTO, C. R.; SEVERO, B. M. A.; WAECHTER, J. L. Composição florística e distribuição ecológica de epífitos vasculares na Floresta Nacional de Passo Fundo, Rio Grande do Sul. Iheringia, Série Botânica, v. 63, n. 2, p. 231-239, 2008.

ESPÍRITO SANTO. Decreto n 1499 -R de 14 de junho de 2005. Diário Oficial Estadual (D.O.E.). Vitória: D.O.E., 2005.

FONTOURA, T. et al. Epífitas vasculares, hemiepífitas e hemiparasitas da Reserva Ecológica de Macaé de Cima. In: LIMA, H. C.; GUEDESBRUNI, R. R., ed. Serra de Macaé: diversidade florística e conservação da Mata Atlântica. Rio de Janeiro: Jardim Botânico do Rio de Janeiro, 1997. p.89-101.

FORZZA, R. C. et al. Bromeliaceae in Lista de Espécies da Flora do Brasil. Jardim Botânico do Rio de Janeiro. 2011. (http:// floradobrasil.jbrj.gov.br/2012/FB006383). 2012.
FRAGA, C. N.; PEIXOTO, A. L. Florística e ecologia das Orchidaceae das restingas do estado do Espírito Santo. Rodriguésia, v.55. n.84, p.5-20, 2004.

FREITAS, J. Flórula das Orchidaceae de São José do Rio Claro, Santa Maria de Jetibá, ES. 2011. 94f. Monografia (Conclusão de Curso) - Escola Superior São Francisco de Assis - ESFA, Santa Teresa/ES, 2011.

FUNDAÇÃO SOS MATAATLÂNTICA; INPE. Atlas dos Remanescentes Florestais da Mata Atlântica - Período 2010-2012. São Paulo: Fundação SOS Mata Atlântica \& Instituto Nacional de Pesquisas Espaciais, 2013.

GENTRY, A. H.; DODSON, C. H. Diversity and biogeography of Neotropical Vascular Ephiphytes. Annals of the Missouri Botanical Gardem, v.74, n.2, p.205-233, 1987.

GIONGO, C.; WAECHTER, J. L. Composição florística e estrutura comunitária de epífitos vasculares em uma floresta de galeria na Depressão Central do Rio Grande do Sul. Revista Brasileira de Botânica, v.27, n.3, p.563-572, 2004.

GiUlietti, A. M. et al. Plantas Raras do Brasil. Belo Horizonte: Conservação Internacional, 2009. 496p.

IUCN. IUCN Red List of Threatened Species. Version 2010.1. Disponível em: <www.iucnredlist.org>. Acesso em 11 de Maio de 2010.

\section{KERSTEN, R. A. Epifitismo vascular na} Bacia do Alto Iguaçu, Paraná. 2006. 218f. Tese (Doutorado em Engenharia Florestal) Universidade Federal do Paraná, Curitiba, 2006.

KERSTEN, R. A.; KUNIYOSHI, Y. S. Conservação das florestas na bacia do Alto Iguaçu, Paraná Avaliação da comunidade de epífitas vasculares em diferentes estágios serais. Floresta, v.39, n.1, p.51-66, 2009.

KERSTEN, R. A.; SILVA, S. M. Composição florística e estrutura do componente epifítico vascular em floresta de planície litorânea na Ilha do Mel, Paraná, Brasil. Revista Brasileira de Botânica, v.24, n.2, p.213-226, 2001. 
KERSTEN, R. A.; SILVA, S. M. Florística e estrutura de comunidades de epífitas vasculares da planície litorânea. In: MARQUES, M. C. M.; BRITEZ, R. M., (Org.) História natural e conservação da Ilha do Mel. Curitiba: Universidade Federal do Paraná, 2005. p.125-144.

LARCHER, W. Ecofisiologia vegetal. São Carlos: Rima, 2006. 550p.

MARTINS, F. R. Estrutura de uma floresta mesófila. Campinas: Universidade de Campinas, 1991. 246p.

MORI, S. A. et al. Manual de manejo do herbário fanerogâmico. 2.ed. Ilhéus: CEPLAC, 1989. 104p.

MUELLER-DOMBOIS, D.; ELLENBERG, H. Aims and methods of vegetation e ecology. New York: Wiley, 1974. 547p.

PEREIRA, J. D. Aspectos ecológicos e anatômicos de epífitas vasculares na trilha do muriqui, Parque Estadual da Serra do Brigadeiro, Araponga Minas Gerais. 2009. 91f. Tese (Doutorado em Botânica) Universidade Federal de Viçosa, Viçosa, MG, 2009.

PEREIRA, U. Z.; RIBEIRO, L. F. Caracterização de comunidades de Orchidaceae em fragmentos de Floresta Ombrófila Densa Montana, em diferentes estágios de regeneração em Santa Teresa, Espírito Santo, Brasil. Natureza online, v.2, n.2, p.52-60, 2004.

PETEAN, M. P. As epífitas vasculares em uma área de Floresta Ombrófila Densa em Antonina, PR. 2009. 75f. Tese (Doutorado em Engenharia Florestal) - Universidade Federal do Paraná, Curitiba, 2009. 75p.

PRADO, J. Polybotrya in Lista de Espécies da Flora do Brasil. Rio de janeiro, Jardim Botânico do Rio de Janeiro, 2012. (http:// floradobrasil.jbrj.gov.br/2012/FB091126). Acesso em: 02 de mar. de 2012.

RECH, A. R.; ROSA, Y. B. C. J.; ROSA-JUNIOR, E. J. Levantamento e características ecológicas de orchidaceae da mata ciliar do Rio Dourados, Dourados-MS. Revista Árvore, v.35, n.3, p.717-724, 2011.
RODRIGUES, T. M. \& SIMONELLI, M. A família Orchidaceae em uma Floresta de Restinga, Linhares-ES: Ecologia e Conservação. Revista Brasileira de Biociências, v.5, S1, p.468-470, 2007.

SANTOS, A. C. L. Composição florística e estrutura da comunidade de epífitas vasculares associadas a trilhas no Parque Estadual das Fontes do Ipiranga, São Paulo, SP, Brasil. 2008. 56f. Dissertação (Mestrado em Biodiversidade Vegetal e Meio Ambiente). Instituto de Botânica da Secretaria de Estado do Meio Ambiente, São Paulo. 2008.

SEFAZ (Secretaria da Fazenda do Espírito Santo). Espírito Santo - Municípios. Disponível em: www.sefaz.es.gov.br/painel/munic34.htm. Acessado em: 13 de Maio de 2010.

SHEPHERD, G. J. FITOPAC 1.6. Campinas: Universidade de Campinas, 2006.

SILVA, E. D.; SANTOS, A. R.; SILVA, K. G. Estudo morfológico e climático dos municípios da região serrana do estado do Espírito Santo. Caminhos de Geografia, v.12, n.39, p.94-103, 2011.

TONHASCA JR., A. Ecologia e Historia Natural da Mata Atlântica. Rio de Janeiro: Interciência, 2005. 197p.

TRIANA-MORENO, L. A. et al. Epífitas vasculares como indicadores de regeneración enbosques intervenidos de la amazônia Colombiana. Acta Biológica Colombiana, v. 8, n.2, p.31-42, 2003.

WAECHTER, J. L. Estudo fitossociológico das orquidáceas epifíticas da mata paludosa do Faxinal, Torres, Rio Grande do Sul. 1980. 104f. Dissertação (Mestrado em Botânica) - Universidade Federal do Rio Grande do Sul, Porto Alegre, 1980.

WENDT, T. et al. Bromeliaceae do município de Santa Teresa, Espírito Santo: lista de espécies, distribuição, conservação e comentários taxonômicos. Boletim do Museu de Biologia Mello Leitão, v.27, p.21-53, 2010.

Revista Árvore, Viçosa-MG, v.37, n.5, p.815-823, 2013 
